\title{
Physical activity: From epidemiological evidence to individualized patient management
}

\author{
Olivier Luc Charansonney ${ }^{\mathrm{a}, *, 1}$, Luc Vanhees ${ }^{\mathrm{b}, 1}$, Alain Cohen-Solal ${ }^{\mathrm{c}, 1}$ \\ a Department of Cardiology, Centre Hospitalier Sud-Francilien, Corbeil-Essonnes, France \\ b Department of Rehabilitation Sciences, KU Leuven, Leuven, Belgium \\ c Department of Cardiology, Hôpital Lariboisière, Paris, France
}

\section{A R T I C L E I N F O}

\section{Article history:}

Received 13 May 2013

Received in revised form 26 September 2013

Accepted 2 November 2013

Available online $\mathrm{xxxx}$

\section{Keywords:}

Physical activity

Physical fitness

Sedentary behavior

Mortality

\begin{abstract}
A B S T R A C T
Background: Physical activity (PA), physical fitness (PF), and even a few sedentary behaviors (SB) are strongly and independently linked to improved survival rate. However, key questions remain: what are the physiological interrelationships between SB, PA, and PF? How should we differently emphasize promoting PA, increasing PF with exercise, and decreasing SB among other prevention measures? What are the interrelationships of both PA and SB levels with drug treatment efficacy?

Methods: To address these questions we developed an integrated patient-centric model combining physiology with epidemiological evidence to characterize the individual risk attached to PA level, PF, and SB. Epidemiological data were collected by extensive literature review.

Results: Nine meta-analyses, 198 cohort studies (3.8 million people), and 13 controlled trials were reviewed.

1. A high level of SB induces chronic stress and increases the risk of both chronic disease and mortality.

2. Vigorous PA increases PF and physiological reserve, thereby improving survival rate. This effect is not mediated by improved traditional risk factors.
\end{abstract}

The risk for most individuals is a mix of high SB, low to mild PA, and low to mild PF.

This model can improve the individualized prescription of PA modalities. Furthermore, the benefit of treatments such as statins or beta-blockers can be cancelled out if a decrease in PA or an increase in SB is induced by drug related side effects.

Conclusions: To improve patient management both types of therapeutic interventions and dose should be carefully chosen for each individual in order to maintain/increase PA level while decreasing SB.

(c) 2013 Elsevier Ireland Ltd. All rights reserved.

\section{Introduction}

The worldwide epidemic of low physical activity (PA) [1] underscores the need for physicians to consider PA a main component of their patients' risk. Epidemiological studies have consistently shown that both a high level of PA and a high level of physical fitness (PF) are strongly linked to improved survival rate. Five days per week of at least 30 min of moderate-intensity PA is recommended for adults [2]. Both American and European guidelines on cardiovascular disease

\footnotetext{
* Corresponding author at: Centre Hospitalier Sud-Francilien, 116 Boulevard Jean Jaurès, 91106 Corbeil-Essonnes, France.

E-mail address: olivier.charansonney@orange.fr (O.L. Charansonney).

1 This author takes responsibility for all aspects of both the reliability and freedom from bias of the data presented and their discussed interpretation.
}

prevention recommend measuring PF by exercise testing for risk assessment $[3,4]$. Finally, a recent European set of recommendations highlights the importance of characteristics and modalities of PA and exercise for cardiovascular health in the general population [5] and in individuals with either CV risk factors [6] or CV disease [7].

However, many practical questions remain, e.g. how much should we emphasize PA compared with other prevention measures? How much should we promote exercise, daily PA, or less sedentary behavior (SB)? What is the impact (if any) of drugs on PA level and how much does it matter? Should we favor pharmacological treatment at clinicaltrial-defined optimal dose over preserving or increasing PA level? Surprisingly, PA is usually superseded in priority order by advising pharmacological treatment and nutrition [8] despite weaker evidence supporting the association of dietary factors with mortality.

To address these practical issues we developed a patient-centric model describing the interaction between PA, PF, SB, and an individual's 
risk of premature mortality. Relevant epidemiological evidence was collected by reviewing the literature.

\section{Method \\ 2.1. Patient-centric model: objective and requirements}

Our main objective is to develop a patient-centric model which integrates epidemiological evidence within a physiological approach. This model should characterize, at the individual level, the lifetime interactions of PA, PF, and SB with mortality risk. PF, a powerful risk predictor, is a fundamental physiological characteristic. PA and SB are two behaviors also linked to premature mortality rate. Interplay between these three components is suspected but should be better characterized.

In order to base our model on solid epidemiological ground, we needed to review epidemiological evidence with a particular interest in the interactions between PA, PF, $\mathrm{SB}$, and mortality rate. We used meta-analyses to quantify these interactions. However, the strength of this quantification is limited in that meta-analyses only take into account the common pieces of information in a limited set of studies. Furthermore, metaanalyses only assess statistical associations between PF, PA, or SB and mortality risk. Interactions between PF, PA, and SB were only taken into account in some studies by using statistical models adjusted for PA or PF whenever measured. Therefore, we needed a more comprehensive approach to collecting information on the interactions between PF, PA, $\mathrm{SB}$, and mortality rate. We conducted an extensive review of published reports on cohort studies and randomized controlled trials evaluating these links (2000-2011), and also conducted a follow-up search up to August, 2013. The objective of the extensive review was both to evaluate the meta-analyses' results' validity in a larger set of populations and to better understand interplay between PA, PA domains, PF, SB, and mortality rate. The objective of the follow-up search was to identify new studies which could substantially modify the results of the previous analysis.

\subsection{Literature review}

Methodology of the extensive review was very similar to the one required for systematic review, with some adaptations related to the objectives.

\subsubsection{Search strategy}

MEDLINE databases and the Cochrane database of systematic reviews were searched for English language publications from 2000 to November 1, 2011. Boolean search was used with the key words: "physical activity and/or fitness and mortality". Citations of interest were independently selected by two reviewers. We also searched the reference list of relevant articles and reviews. Reports selected by at least one reviewer were included and full-texts were analyzed in-depth.

The same databases were regularly searched up to August, 2013 (follow-up search), with review of the titles and abstracts of relevant articles.

\subsubsection{Inclusion criteria}

Meta-analyses assessing the strength of the links between PF, PA or SB and mortality rate were identified and analyzed.

Prospective cohort studies and randomized studies assessing the links between either PA or PF with mortality were selected for the extensive review. For each report selected from the literature search, the prospective cohort on which the study was run was identified and relevant information was collected either from the report or from other related sources such as publications or websites. Screened reports which did not provide information on mortality rate were used for the identification of the related cohort. Other reports on this related cohort were then searched for mortality data.

Reports identified with the same search strategy during the follow-up search were selected based on title and abstract, and on full-text article if necessary. Relevant pieces of information from these articles were included in the present work, but not in the extensive review.
2.2.3. Data extraction

Data were extracted from the relevant sources including selected reports and related publications. The following data were extracted: name of first author and year, cohort name and characteristics (country, type of population included, type of cohort), number age, men/women, condition/disease, PA/PA subtypes/PF/SB measurement protocols, follow-up, type of mortality, results (semi-quantitative: positive, negative association, neutral result, trend), gradient effect, and temporal relationships.

\subsubsection{Quality assessment}

The following data enable a quality assessment of each cohort: whether representative, population-based, or based on disease condition, age and sex distribution, followup, type of assessment of PA, PF, or protocol used. Since there is a large discrepancy in adjustment variables across the studies, we chose to base our semi-quantitative analysis on age and sex adjusted models. However, these results were not provided in several studies, so in those cases we used the least adjusted model. Consistency between the several reports on the same cohort was checked.

\subsubsection{Publication bias}

A formal analysis such as funnel plot is not possible because of the heterogeneity of the results' presentation. As previously described, we tried to identify all the cohorts which collect data on PA, PF or SB through protocol publications and web-sites.

\section{Results}

We first describe the relevant epidemiological information and then lay out the model's characteristics and its usefulness for patient management.

Nine meta-analyses [9-17], including from 3600 to 980,000 individuals, 198 cohort studies totaling 3.8 million people included in 105 cohorts, and 12 randomized studies were analyzed in depth. Studies' characteristics are summarized in Tables 1 \& 2 (details in online supplementary material). Seventy seven reports on cohort studies and one on randomized controlled trial were identified during the follow-up search. Full-texts of these reports were screened and results included if relevant. The Prisma flow diagram is shown in Fig. 1.

\subsection{Epidemiological studies have clearly shown that both PF and PA are independently linked to mortality}

One metabolic equivalent (MET) increase in PF is associated with a $13 \%$ decrease in the risk of premature mortality [13]. Similarly, a recent cohort study found that a one-MET increase in PF during a 12-week cardiac rehabilitation program is associated with a $13 \%$ reduction in mortality [18].

Each activity which contributes to PA has an assigned energy expenditure (MET) which is multiplied by the time (h) spent in this activity (Table 3). Both total PA and the various PA domains are associated with lower mortality rate [15], and an inverse relationship between MET-h/week and all-cause mortality rate has been found [16]. This relation appears to be nonlinear with the benefit being greater for 11 MET-h/week of light-to-moderate PA compared with 0 MET-h (19\% reduction in the risk of premature mortality), and with a smaller incremental benefit for higher levels of PA: 31 MET-h/week of moderate PA is

Table 1

Characteristics of meta-analyses.

\begin{tabular}{|c|c|c|c|c|c|c|c|}
\hline 1st author/year & Exposure & Citations identified & Reports included & Individuals (in mortality studies) & Age at inclusion & Follow-up (years) & Results (RR) \\
\hline Cooper, 2010 & Walking speed & 2270 & $28(1.2 \%)$ & 14,692 & $61->70$ & $3-5$ & 0.35 \\
\hline Davies, 2010 & Exercise training (RCT) & 11,561 & $23(0.2 \%)$ & 3647 & $43-72$ & $0.5-5$ & 0.91 (ns) \\
\hline Grontved, 2011 & Television viewing & 1655 & $8(0.5 \%)$ & 26,509 & $>25$ & 8 & $1.13^{*}$ \\
\hline Hamer, 2008 & Walking pace & 4295 & $18(0.4 \%)$ & 147,063 & $20-93$ & 11 & 0.68 \\
\hline Kodama, 2009 & $\mathrm{PF}$ & 10,679 & $33(0.3 \%)$ & 102,980 & $37-57$ & $1-26$ & 0.59 \\
\hline Nocon, 2008 & $\mathrm{PF} / \mathrm{PA}$ & 1768 & $33(1.9 \%)$ & 883,372 & na & $4-20$ & $\begin{array}{l}0.59(\mathrm{PF}) \\
0.71(\mathrm{PA})\end{array}$ \\
\hline Samitz, 2011 & PA domains & 6933 & $80(1.2 \%)$ & 844,026 & 56 & 11 & 0.65 \\
\hline Taylor, 2004 & Exercise training $(\mathrm{RCT})$ & $>5000$ & $48(1 \%)$ & 8940 & 55 & 1.5 & 0.80 \\
\hline Woodcock, 2010 & PA & 6210 & $22(0.4 \%)$ & 977,925 & $38-72$ & $5-25$ & 0.76 \\
\hline
\end{tabular}

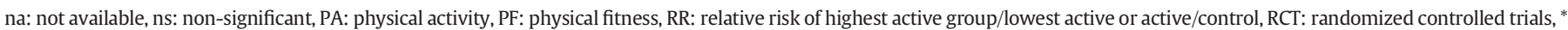
RR per 2 hours of TV viewing per day. 
Table 2

Characteristics of cohort studies and randomized trials.

\begin{tabular}{|c|c|c|c|c|c|c|c|}
\hline & Studies & Cohorts & Individuals & Age (years) & Follow-up (years) & Regions & Characteristics at inclusion* \\
\hline \multirow[t]{3}{*}{ PF } & 74 & 25 & 170,000 & 49 & 14 & USA: $81 \%$ & Women: $13 \%$ \\
\hline & & & & & & Korea: $11 \%$ & T2DM: $5 \%$ \\
\hline & & & & & & Europe: 7\% & CVD: $2 \%$ \\
\hline \multirow[t]{5}{*}{ PA } & 163 & 94 & $2,300,000$ & 55 & 13 & USA: $42 \%$ & Women: $48 \%$ \\
\hline & & & & & & Asia: $31 \%$ & Elderly: $20 \%$ \\
\hline & & & & & & Europe: $26 \%$ & T2DM: $1 \%$ \\
\hline & & & & & & & CVD: $1 \%$ \\
\hline & & & & & & & Breast cancer: $1 \%$ \\
\hline \multirow[t]{2}{*}{ RCT } & 12 & 12 & 4,135 & 56 & $0.3-11$ & & Women: $34 \%$ \\
\hline & & & & & & & HF: $78 \%$ \\
\hline
\end{tabular}

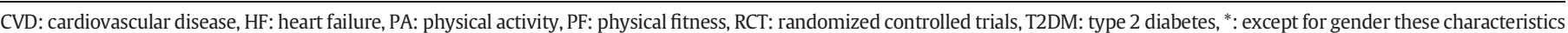
wer required for inclusion in specific studies.

associated with a $24 \%$ reduction in the risk of premature mortality compared with 0 MET-h [16].

Results of the cohort studies were consistent with meta-analyses'. All 25 cohorts which measured PF found a positive association between PF and survival rate. PA was assessed in 94 cohorts, and only 3 small cohorts of specific populations (chronic kidney disease, breast cancer, and diabetes) failed to show a statistically significant association between PA level and survival rate [19-21]. Two studies in Danish workers found a negative association between occupational PA and survival rate in men, and a neutral association in women [22] [23]. Finally, a study in a small group of patients with both diabetes and proteinuria found a negative association between PA and survival rate [24]. To our knowledge, this result has not been confirmed in any other study.

Each 2-h increase of TV watching is associated with a 13\% increase in mortality rate [11]. Twenty three cohorts assessed SB, with 7 (30\%) reporting results showing a negative association between SB and survival rate in all but one study in California retirees. In the latter, watching TV was associated with a lower mortality risk in younger retired women and older men. Watching TV is neutral in the whole cohort [25].

Randomized controlled trials generally failed to show a benefit of exercise training on mortality both in individual analyses and in metaanalyses [10]. Interactions at the individual level between PF, PA, and SB might partially explain these results. We will develop this point in the next paragraph.

Interestingly, both walking velocity [12] and intensity of cycling [26] are more powerfully related to mortality than the duration of either activity.

From a physiological point of view, both high velocity walking and cycling are conditioning PA which can significantly increase PF.
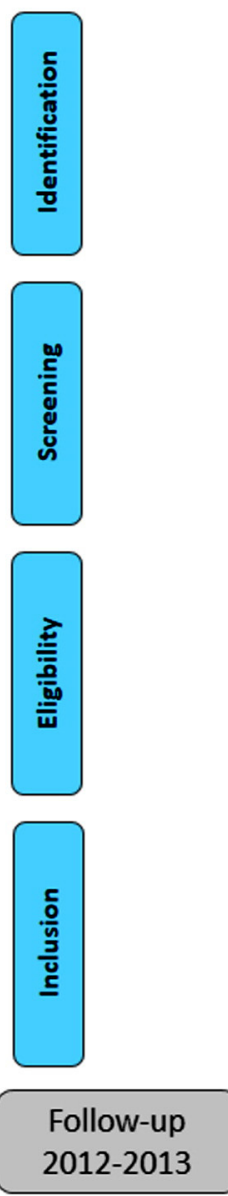
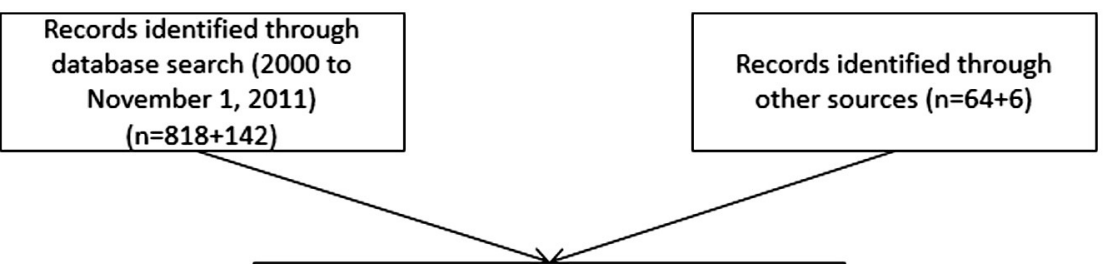

Records after duplicates removed $(n=882+148)$
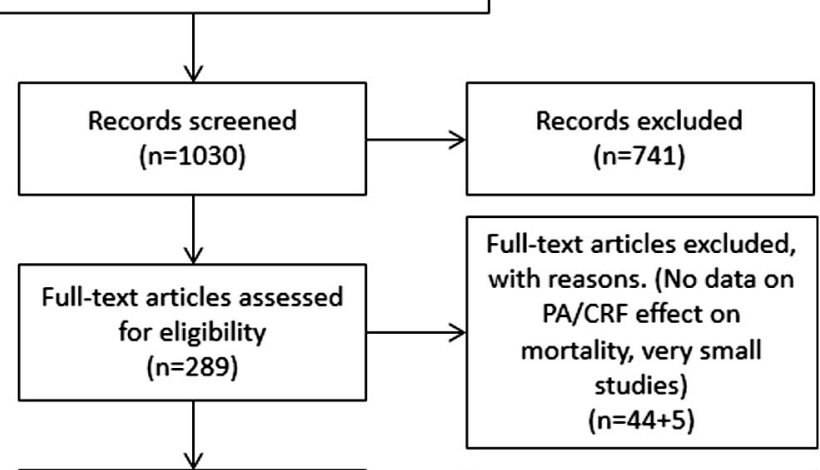

Studies included in qualitative synthesis $(n=210)$

Several articles per study $(n=30)$

New reports on cohort studies \& randomized trials ( $n=24 \& 1)$

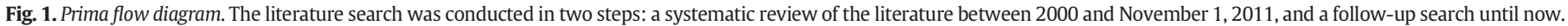


Table 3

Definitions and landmark values.

\begin{tabular}{|c|c|}
\hline Energy expenditure (definition) & \\
\hline $1 \mathrm{Kcal}=4.187$ Joules $(\mathrm{j})$ & \\
\hline Energy expenditure at rest & $\begin{array}{l}1 \mathrm{MET}=3.5 \mathrm{mlO} 2 / \mathrm{min} / \mathrm{kg}= \\
0.018 \mathrm{Kcal} / \mathrm{min} / \mathrm{kg}=20.5 \mathrm{Watts}\end{array}$ \\
\hline Burning $1 \mathrm{lO}_{2}$ (glucid metabolism) & $21 \mathrm{Kj}$ or $0.005 \mathrm{Kcal}$ \\
\hline Spending 1 MET during one hour & $1 \mathrm{MET} / \mathrm{h}$ \\
\hline Sedentary behavior (examples) & \\
\hline$<1.5$ METS & $\begin{array}{l}\text { - Sitting time } \\
\text { - Car time } \\
\text { - Screen time }\end{array}$ \\
\hline Levels of physical activity (example & \\
\hline Light 1.5-2.9 METS & $\begin{array}{l}\text { - Walking slowly } \\
\text { - Sitting } \\
\text { - Standing and performing light work } \\
\text { - Playing cards } \\
\text { - Fishing ( sitting) } \\
\text { - Playing most musical instruments }\end{array}$ \\
\hline Moderate 3.0-6.0 METS & $\begin{array}{l}\text { - Walking (brisk) } \\
\text { - Heavy cleaning } \\
\text { - Light bicycling } \\
\text { - Dancing } \\
\text { - Golf (pulling clubs) }\end{array}$ \\
\hline Vigorous $>6$ METS & $\begin{array}{l}\text { - Jogging, running } \\
\text { - Carrying heavy load } \\
\text { - Heavy farming } \\
\text { - Swimming (moderate to heavy) }\end{array}$ \\
\hline
\end{tabular}

Weekly energy expenditure for a man weighting $70 \mathrm{~kg}$

$\begin{array}{ll}\text { Basal metabolism } & 168 \mathrm{MET}-\mathrm{h}=14,000 \mathrm{Kcal} \\ \text { - Minimal recommended physical activity } & 10 \mathrm{MET}-\mathrm{h}=740 \mathrm{Kcal} \\ \quad(5 \times 30 \text { min moderate or } 3 \times 20 \mathrm{~min} & \\ \quad \text { vigorous }) & \\ \text { - Most "Exercisers" ( } 2 \mathrm{~h} / \mathrm{w}) & \\ \text { - Cardiac rehabilitation }(1.5 \text { to } 3 \mathrm{~h} / \mathrm{w}) & \\ \begin{array}{l}\text { Training for non-professional endurance } \\ \text { running ( } 6 \mathrm{~h} \text { at } 11 \mathrm{~km} / \mathrm{h})\end{array} & 60 \mathrm{MET}-\mathrm{h}=4400 \mathrm{Kcal} \\ \begin{array}{l}\text { Active versus sedentary work } \\ \text { Amish adults (Labor-intensive farming) [30] }\end{array} & 100 \mathrm{MET}-\mathrm{h}=7400 \mathrm{Kcal} \\ & \end{array}$

Weekly energy “saving” with sedentary behaviors [24]

Obese versus lean sedentary behavior

( $2 \mathrm{~h}$ less of standing and walking)

Sedentary versus active non-exercise

Minus $2500 \mathrm{Kcal}=34 \mathrm{MET}-\mathrm{h}$

physical activity

Up to minus $7000 \mathrm{Kcal}=95 \mathrm{MET}-\mathrm{h}$

\subsection{Statistically independent links do not imply a lack of interaction at an individual's level}

For instance, a very moderate PA in an individual with a low PF level can increase compensatory SB. Conversely, after resuming regular PA a previously active individual who has had to retrain his/her activity after an injury can both improve his/her mood and decrease SB. In fact, several pieces of epidemiological evidence suggest such interactions.

The effect of work-related PA varies everywhere from worsening impact on mortality [23] to improving the impact [27]. PA-SB interactions might explain parts of these results. For instance, on one hand perceived physical exertion at work can increase the risk of long term sickness [28], but on the other hand, increasing the use of stairs at work can improve an individual's risk profile [29]. This could be explained by the fact that high physical demand at work may increase leisure time SB and decrease PA. Both effects contribute to an individual's increased mortality risk even if each component has too weak an effect to influence adjusted correlation between work-related PA and mortality. Therefore, this link appeared to be independent from leisure time PA
[23]. Increasing the use of stairs decreases SB at work and thereby decreases the mortality risk. Furthermore, using stairs can increase PF [29].

Importantly, increasing PA with structured programs such as rehabilitation or sports can decrease unstructured PA [30] and increase SB, contributing to the difficulty of demonstrating exercise-based rehabilitation's benefit on mortality rate in randomized trials [30] [31].

3.3. An integrated individual-centric model describing the interrelationships between $P A, S B, P F$, and premature mortality (Fig. 2)

The risk of premature mortality is strongly and inversely linked to the physiological reserve of which PF is a major component.

SB and a low level of PA activate inappropriate stress responses through mechanisms that we previously described (Fig. 3) [32]. These mechanisms induce hypercoagulability, platelet hyperaggregability, and chronic inflammation, eventually leading to chronic disease. Conversely, vigorous, high intensity PA can improve PF, thereby increasing physiological reserve. This model can explain the non-linear relationships between PA, PA components, and mortality. At one end of the spectrum improvements in cardiovascular risk factors by high intensity PA are mainly mediated by PF [33]. However, the benefit of a high level of PF on mortality is unlikely to be mediated by traditional risk factors [13] and we speculate that this benefit is mainly due to the high physiological reserve in individuals with high PF. At the other end, a high percentage of sedentary time has been associated with a large, 3-fold, increase in the risk of having metabolic syndrome [34]. Furthermore, C-reactive protein explained $18 \%$ of the association between screentime and cardiovascular events [35]. Therefore, the risk associated with a sedentary lifestyle appears mediated by cardiometabolic and inflammatory risk factors.

\subsection{How various modalities of PA can influence mortality (Table 4)}

A high intensity short duration of exercise increases PF; however, its effect on overall PA might be very small if no other PA modality is associated. For instance, 6 bouts of $0.5 \mathrm{~min}$ runs at $19 \mathrm{~km} / \mathrm{h}$ each day (an unlikely scenario) will increase weekly PA by less than 7 MET-h. In the meantime, such high intensity PA could increase compensatory SB. The benefit will probably be mainly associated with high PF and could be mitigated by increased SB.

Conversely, long walks at low-moderate intensity can greatly increase the volume of PA. For instance, walking $8 \mathrm{~h} / \mathrm{day}$ at $2 \mathrm{~km} / \mathrm{h}$ (16 km/day) will increase weekly PA volume by 112 MET-h. Furthermore, daytime opportunities for SB will be reduced. Benefit will mainly be associated with both increased PA volume and reduced SB.

Short walking activity at high speed will bring moderate beneficial effects by increasing both PF and weekly PA volume with no or only slight increase in SB. This level of activity corresponds to current recommendations of $30 \mathrm{~min}$ of brisk walking at least five days per week.

\section{Lifetime interactions between physical activity, physical fitness and physiological reserve drive an individual's risk of mortality}

Fig. 4 illustrates the lifetime interactions between PF, PA, and SB, with trajectories for two hypothetical middle-aged men ( 50 years old at the beginning and weighing $70 \mathrm{~kg}$ ). The first is a nonprofessional competing athlete with a high PF level varying according to training intensity. He is able to achieve a work load of 300 Watts (15 METs) on a cycle-ergometer. Such a level of PF can be maintained with $6 \mathrm{~h}$ of training per week, with energy expenditure up to 60 MET-h/week. However, plenty of time remains for SB ( 160 h/week). Despite his high level of PF, this individual can have both a highly sedentary lifestyle and a relatively low PA level. If this man has an active job instead of a sedentary one, his daily energy expenditure can increase by $~ 100$ MET-h/week, far more than what he is spending during his training [36]. Conversely, if he has a sedentary job and adopts SB, he 


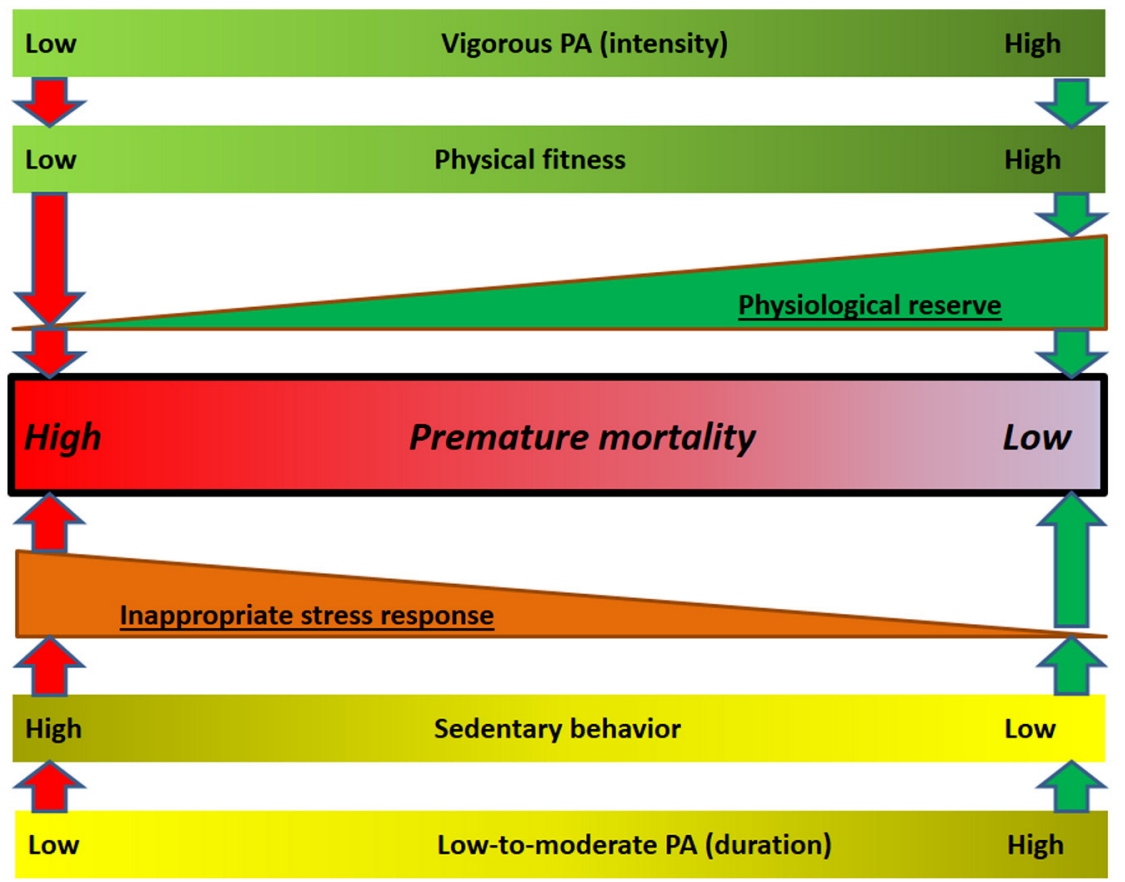

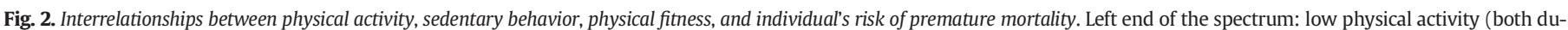

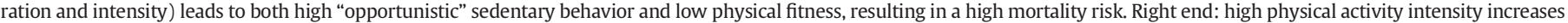
physical fitness and physiological reserve, lowering mortality risk. This benefit is further increased by long physical activity duration and low sedentary behavior.

can spend from 30 to 200 MET-h less per week! [36] Therefore, even a high level of exercise training can be associated with a very significant risk of premature mortality associated with both SB and low PA level.

The second man can achieve a workload of 185 Watts (9 METs) on a cycle-ergometer. He can perform any type of PA up to moderately high physical exercise. Like most exercisers he participates in exercise for less than $2 \mathrm{~h}$ a week, spending less than 10 MET-h. He depends mainly on non-exercise moderate PA to maintain his PF level (conditioning activities). His risk profile is driven by both his moderate PA [16] and his SB, but also by his average PF which limits his physiological reserve. After a first cardiovascular event (for example, acute ischemic event with cardiac failure) his PF level sharply decreases and only partly recovers with treatment, including drugs and rehabilitation (generally 1.5 to $3 \mathrm{~h} /$ week in 3 to 5 sessions), which might increase energy expenditure by up to $10 \mathrm{MET}$-h/week ( 5 sessions of $40 \mathrm{~min}$ at 70\% of CRF). Rehabilitation can slightly improve PF but without proven significant impact on mortality [31]. As previously mentioned, an increase in SB and/or a decrease in non-exercise PA during a rehabilitation program can jeopardize the benefit of exercise training. Despite partial recovery, he remains short of breath during moderate PA (NYHA class 2). A subsequent event (heart failure) further decreases his PF, impairing his ability to perform even daily activity (NYHA class 3 ) and leads to a state of frailty [37] [38].

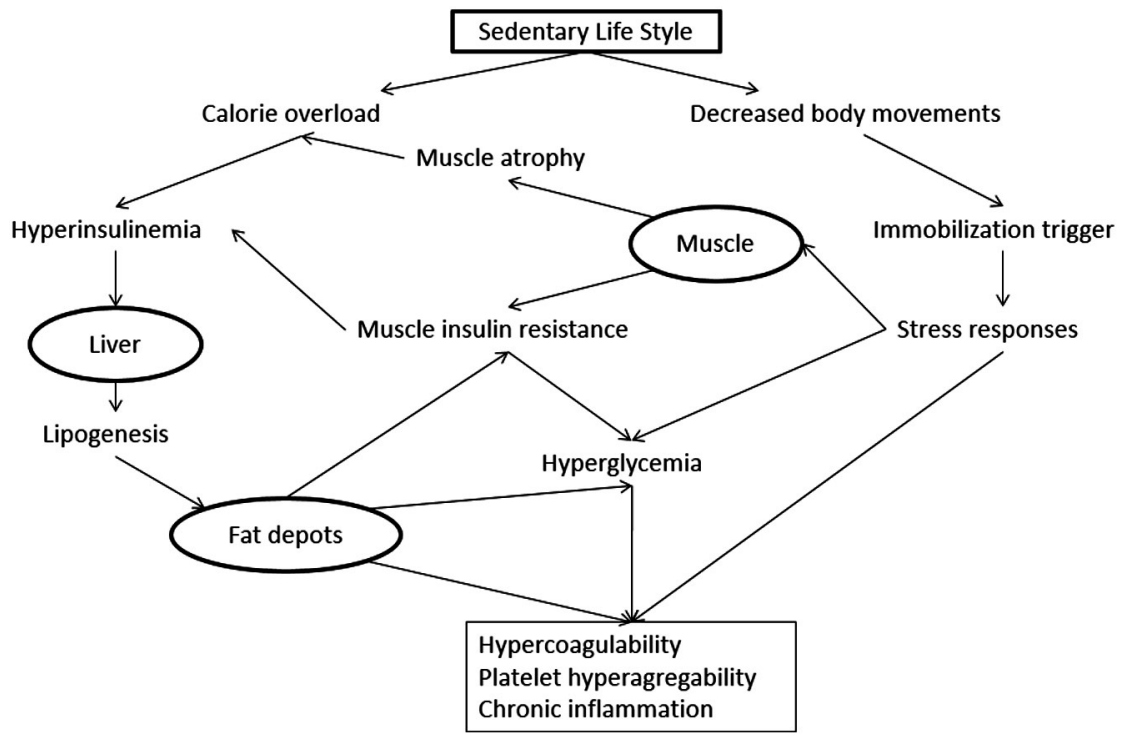

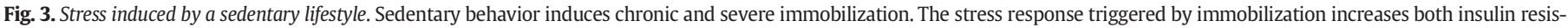

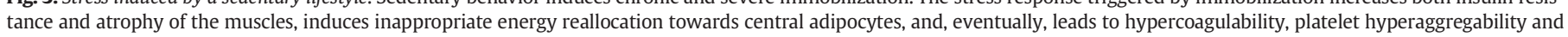
chronic inflammation (Charansonney and Després, 2010). 
Table 4

Effects of various modalities of physical activity on determinants of premature mortality.

\begin{tabular}{llll}
\hline PA modalities & $\begin{array}{l}\text { Effect } \\
\text { on PF }\end{array}$ & $\begin{array}{l}\text { Effect } \\
\text { on PA }\end{array}$ & $\begin{array}{l}\text { Effect } \\
\text { on SB }\end{array}$ \\
\hline High intensity, short duration & +++ & + & $+/-$ \\
Low intensity, very long duration (walking all day) & $\mathrm{NE}$ & +++ & -- \\
Moderate intensity, moderate duration & + & ++ & $+/-$
\end{tabular}

PA: physical activity, PF: physical fitness, SB: sedentary behavior.

+++ : strong increase, ++ : moderate increase, + : modest increase, -- : decrease; $+/-$ : possible increase or decrease, NE: no effect.

\section{Clinical management of individuals: promoting PA should have the highest priority}

\subsection{A key step is to identify the barriers to PA}

Lack of time is frequently brought forward. Emphasis on the usefulness of non-exercise PA such as walking to work or using stairs can help overcome this objection. Health conditions are often considered a barrier by elderly individuals. Osteoarthritis, back pain, and dizziness are among the most common. Lack of interest, lack of company, spouse's condition, fatigue, or depression also often limits PA. It should be strongly emphasized that almost all of the health conditions perceived as a barrier to PA can be improved by PA. Furthermore, conditions such as depression contribute to low treatment compliance, whatever the treatment is.

\subsection{Improving treatment choice to increase $P A$}

In a significant number of cases, management of inhibiting conditions such as osteoarticular pain, or depression, might have the highest priority over other treatments. When applying this approach, treatment choice and dose optimization should be driven by the drug's side effects on the individual and not by the drug's statistically defined target dose. On one hand, higher doses of statin seem to have a larger benefit for preventing cardiovascular events but have no unequivocally significant effect on mortality [39]. On the other hand, statins can induce dose-dependent muscle pain, and can increase susceptibility to exercise-induced muscle injury, so higher doses of statin may limit PA and increase compensatory SB [40]. Therefore, since both a low level of PA [16] and a higher level of SB [11] are associated with an increased risk of premature mortality, the dose of statin should be adjusted for each individual so that the highest possible PA level can be achieved (Fig. 5) [41] [42]. Furthermore, we should ensure that drug-induced symptoms do not impair the efficacy of exercise-based rehabilitation, since rehabilitation may decrease the risk of mortality in individuals with coronary heart disease [17]. It is possible that beta-blockers may also limit exercise tolerance in some individuals: however, beta-blockers greatly improve survival in patients with heart failure, and have an almost neutral effect on exercise capacity. Indeed, a meta-analysis of randomized controlled trials found that beta-blockers' benefit on mortality in patients with heart failure is related to patient heart rate, not to beta-blocker dose [43]. Therefore, beta-blocker dose optimization should be based on an individual's heart rate and his/her tolerance of such factors as dizziness, fatigue, and hypotension [44]. Not surprisingly, beta-blocker mean doses used in real life cohorts of elderly patients with heart failure tend to be lower than the doses used in randomized trial cohorts of usually younger patients with fewer comorbidities.

Screening, diagnosis, and optimal management of sleep apnea are also critical to limiting day-time fatigue, sleepiness, and induced SB. Similarly, the use of psychotropic drugs for treatment of insomnia, anxiety, or depression should carefully avoid side effects impairing PA and promoting SB (sleepiness, orthostatic hypotension ...). Table 5 lists some commonly prescribed drugs whose side effects can impair PA.

Rehabilitation programs focused on improving gait, osteoarticular or cardiovascular conditions can be used to break the vicious cycle of health-barrier-to-physical-activity and SB.

\section{Discussion}

Our model is established on strong epidemiological associations between PA, PF, SB, and premature mortality rate. These associations are found in both men and women, in patients of many age-classes, with various disease conditions and with various cultural backgrounds. However, the lack of consistent effect of rehabilitation, e.g. systematic increase of PF, on mortality in randomized controlled trials preclude definite conclusion on the causation between PF and mortality. Still,

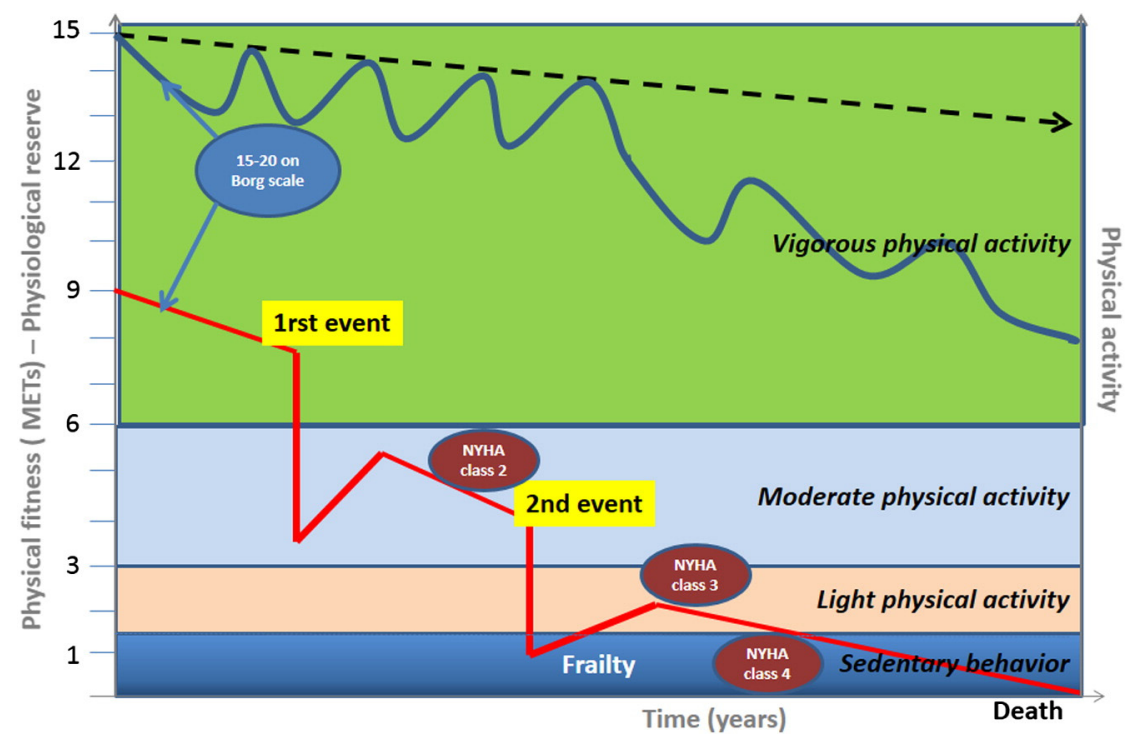

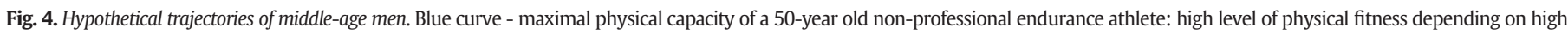

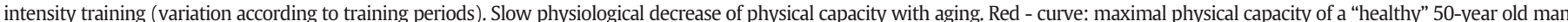

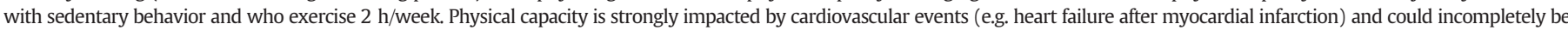

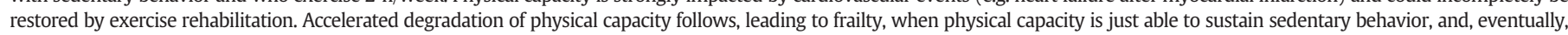
death. NYHA: New York Health Association class 2: dyspnea during moderate physical activity, class 3: dyspnea during daily activity (based on Buchner, 1992 and Charansonney, 2011). 


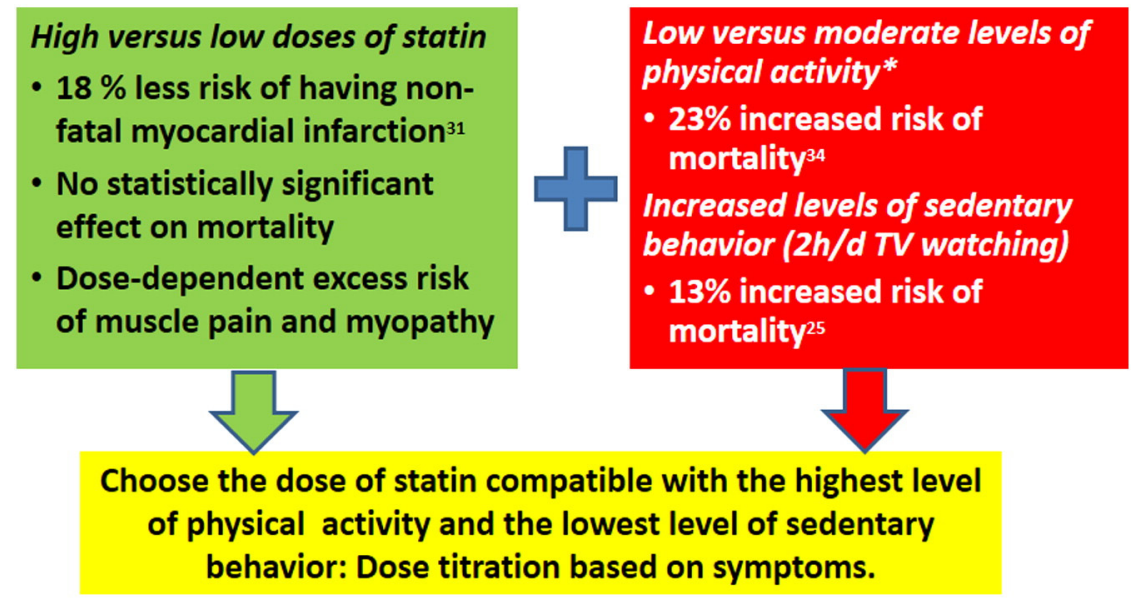

* 2.5 hours per week of moderate physical activity

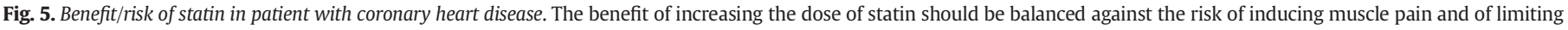
physical activity.

our model suggests that interactions at the level of the individual between PF, PA, and SB might explain non-conclusive clinical trial results. This is physiologically plausible. New clinical trials should specifically analyze interactions between PF, PA, SB, and intervention at the individual level to test this hypothesis.

One limit of our model is the lack of quantitative estimation of absolute mortality risk. PF can be objectively measured. However, there is a need for determining normative PF levels in large and representative population samples [45]. PA and SB, both behaviors, are far more difficult to measure and may be highly influenced by the socio- cultural environment. Despite these limitations, we think that available data could be integrated with a semi-quantitative approach, such as the one used in our model, in order to help patient management.

The absence of randomized trial positive results weakens the estimation of PA/PF's increased benefit compared with drug efficacy. Therefore, benefit/risk ratio comparisons such as the one shown in Fig. 5 can be challenged. Statin benefit on mortality has not been unequivocally established [39]. Furthermore, some large controlled trials evaluating the effect of different statin doses only included a small percentage of the eligible population [46]. Therefore, established benefits of highly

Table 5

Potential impact on physical activity of drugs commonly prescribed to patients with cardiovascular disease.

\begin{tabular}{|c|c|c|c|}
\hline Class of drugs & Expected therapeutic benefit & Side effects impacting PA & Potential mechanisms \\
\hline \multirow[t]{4}{*}{ Beta-blockers } & Improve survival in HF, Decrease & Limit heart rate reserve & Limit adaptation to exercise \\
\hline & blood pressure & Weight gain (atenolol, ASCOT) & Limit non-exercise PA (increase weight) \\
\hline & & Adverse effect on lipid and glucid metabolism & Increase risk of fall (hypotension) \\
\hline & & Dizziness, asthenia, bronchospasm & Limit outdoor activities (gait instability) \\
\hline \multirow[t]{3}{*}{ Diuretics } & Improve survival in HT, Improve & Adverse effect on lipid metabolism & Limit outdoor activities (diuresis) \\
\hline & symptoms in $\mathrm{HF}$ & & Sleep disturbance (diuresis) \\
\hline & & $\begin{array}{l}\text { Increase diuresis and micturition. } \\
\text { Orthostatic hypotension }\end{array}$ & Increase risk of fall (hypotension) \\
\hline \multirow{2}{*}{ ACE inhibitors } & Improve survival in $\mathrm{HT}$ and $\mathrm{HF}$ & $\begin{array}{l}\text { Urthostatic hypotension } \\
\text { Hypotension }\end{array}$ & Increase risk of fall (hypotension) \\
\hline & & Cough & Sleep disturbance (cough) \\
\hline Angiotensin II receptor antagonists & $\begin{array}{l}\text { Improve survival in HF, Decrease } \\
\text { blood pressure }\end{array}$ & Hypotension & Increase risk of fall (hypotension) \\
\hline \multirow[t]{2}{*}{ Calcium antagonists } & Improve survival in HT & Hypotension, leg swelling & Increase risk of fall (hypotension) \\
\hline & & & Pain in the legs \\
\hline Aldosterone antagonists & $\begin{array}{l}\text { Improve survival in HF, Decrease } \\
\text { blood pressure }\end{array}$ & Sleepiness, gastrointestinal & Sleepiness \\
\hline \multirow[t]{2}{*}{ Statins } & Improve survival & Muscle injury & Limit exercise (muscle pain) \\
\hline & & & Sleep disturbance (muscle pain) \\
\hline Metformin & T2DM (blood glucose control) & Gastrointestinal & Limit outdoor activities (GI) \\
\hline \multirow[t]{3}{*}{ Insulins } & DM (blood glucose control) & Weight gain, hypoglycemia & Limit outdoor activities \\
\hline & & Need for glucose monitoring & Increase risk of fall (hypoglycemia) \\
\hline & & & $\begin{array}{l}\text { Limit autonomy (injection and blood } \\
\text { glucose monitoring) }\end{array}$ \\
\hline Sulfonyl ureas & T2DM (blood glucose control) & Hypoglycemia & Increase risk of fall (hypoglycemia) \\
\hline DPP4 inhibitors & T2DM (blood glucose control) & & \\
\hline GLP-1 agonists & T2DM (blood glucose control) & $\begin{array}{l}\text { Weight loss, nausea } \\
\text { Injectable }\end{array}$ & Improve physical well-being \\
\hline Aspirin & Improve survival & Hematoma & Limit type of exercise (trauma) \\
\hline P2Y12 inhibitors & Improve survival & Hematoma & Limit type of exercise (trauma) \\
\hline \multirow[t]{2}{*}{ Anti-vitamin K } & Decrease risk of stroke (AF) & Hematoma & Limit type of exercise (trauma) \\
\hline & & & Limit autonomy (blood test monitoring) \\
\hline New oral anticoagulants & Decrease risk of stroke (AF) & Hematoma & Limit type of exercise (trauma) \\
\hline SSR inhibitors & Treat depression symptoms & Asthenia, weight gain, sleepiness, dizziness & $\begin{array}{l}\text { Limit non-exercise physical activity } \\
\text { Increase risk of fall (dizziness) }\end{array}$ \\
\hline
\end{tabular}

AF: Atrial fibrillation; HF: Heart failure; HT: Hypertension; PA: Physical activity; T2DM: Diabetes mellitus (type 2). 
studied drugs such as statins have often limited validity especially in populations usually excluded from clinical trials, such as elderly with co-morbidities. Given these limitations for both PA/PF interventions and drugs' therapeutic benefits we think that a comparative approach using the existing data is legitimate and can improve patient management.

\section{Conclusion}

The sedentary life style syndrome is the result of three relatively independent factors: a low or decreasing PF, a low level of PA and a high level of SB. These three components should be considered together when designing public health policies or managing individual patients. Otherwise, the benefit obtained in improving one of these factors (e.g. exercise-related $\mathrm{PA}$ ) can be counterbalanced by negative impact on the others (e.g. decreasing non-exercise PA and increasing SB). The impact of drug treatments on PA and SB should be carefully assessed both when managing an individual patient and, ideally, when evaluating treatment strategies including those strategies to be used in drug development studies.

The beauty of giving the fight against sedentary lifestyle all its deserved consideration is that it brings a clear and simple way of prioritizing both drug and non-drug treatment strategies, enabling us to choose drugs for optimizing benefit/risk ratio on an individual basis.

\section{Acknowledgments}

We thank Patricia Montiel for her assistance in selecting published reports and Bill Piper for his English language editorial assistance.

\section{Appendix A. Supplementary data}

Supplementary data to this article can be found online at http://dx. doi.org/10.1016/j.ijcard.2013.11.012.

\section{References}

[1] Kohl III HW, Craig CL, Lambert EV, et al. The pandemic of physical inactivity: global action for public health. Lancet 2012;380(9838):294-305.

[2] Nelson ME, Rejeski WJ, Blair SN, et al. Physical activity and public health in older adults: recommendation from the American College of Sports Medicine and the American Heart Association. Circulation 2007;116(9):1094-105.

[3] Greenland P, Alpert JS, Beller GA, et al. 2010 ACCF/AHA guideline for assessment of cardiovascular risk in asymptomatic adults: a report of the American College of Cardiology Foundation/American Heart Association Task Force on Practice Guidelines. Circulation 2010;122(25):e584-636.

[4] Perk J, De Backer G, Gohlke H, et al. European Guidelines on cardiovascular disease prevention in clinical practice (version 2012): The Fifth Joint Task Force of the European Society of Cardiology and Other Societies on Cardiovascular Disease Prevention in Clinical Practice (constituted by representatives of nine societies and by invited experts) * Developed with the special contribution of the European Association for Cardiovascular Prevention \& Rehabilitation (EACPR). Eur Heart J 2012;33(13):1635-701.

[5] Vanhees L, De Sutter J, Gelada SN, et al. Importance of characteristics and modalities of physical activity and exercise in defining the benefits to cardiovascular health within the general population: recommendations from the EACPR (Part I). Eur J Prev Cardiol 2012;19(4):670-86.

[6] Vanhees L, Geladas N, Hansen D, et al. Importance of characteristics and modalities of physical activity and exercise in the management of cardiovascular health in individuals with cardiovascular risk factors: recommendations from the EACPR. Part II. Eur J Prev Cardiol 2012;19(5):1005-33.

[7] Vanhees L, Rauch B, Piepoli M, et al. Importance of characteristics and modalities of physical activity and exercise in the management of cardiovascular health in individuals with cardiovascular disease (Part III). Eur J Prev Cardiol 2012;19(6):1333-56.

[8] Ezzati M, Riboli E. Can noncommunicable diseases be prevented? Lessons from studies of populations and individuals. Science 2012;337(6101):1482-7.

[9] Cooper R, Kuh D, Hardy R, Mortality Review Group. Objectively measured physical capability levels and mortality: systematic review and meta-analysis. BMJ 2010:341.

[10] Davies EJ, Moxham T, Rees K, et al. Exercise training for systolic heart failure: Cochrane systematic review and meta-analysis. Eur J Heart Fail 2010;12(7):706-15.

[11] Grøntved A, Hu FB. Television viewing and risk of type 2 diabetes, cardiovascular disease, and all-cause mortality. JAMA 2011;305(23):2448-55.

[12] Hamer M, Chida Y. Walking and primary prevention: a meta-analysis of prospective cohort studies. Br J Sports Med 2008;42(4):238-43.

[13] Kodama S, Saito K, Tanaka S, et al. Cardiorespiratory fitness as a quantitative predictor of all-cause mortality and cardiovascular events in healthy men and women: a meta-analysis. JAMA 2009;301(19):2024-35.
[14] Nocon M, Hiemann T, Muller-Riemenschneider F, Thalau F, Roll S, Willich SN. Association of physical activity with all-cause and cardiovascular mortality: a systematic review and meta-analysis. Eur J Cardiovasc Prev Rehabil 2008;15(3):239-46.

[15] Samitz G, Egger M, Zwahlen M. Domains of physical activity and all-cause mortality: systematic review and dose-response meta-analysis of cohort studies. Int Epidemiol 2011;40(5):1382-400.

[16] Woodcock J, Franco OH, Orsini N, Roberts I. Non-vigorous physical activity and allcause mortality: systematic review and meta-analysis of cohort studies. Int J Epidemiol 2010;40(1):121-38.

[17] Taylor RS, Brown A, Ebrahim S, et al. Exercise-based rehabilitation for patients with coronary heart disease: systematic review and meta-analysis of randomized controlled trials. Am J Med 2004;116(10):682-92.

[18] Martin B-J, Arena R, Haykowsky M, et al. Cardiovascular fitness and mortality after contemporary cardiac rehabilitation. Mayo Clin Proc 2013;88(5):455-63.

[19] Emaus A, Veierod MB, Tretli S, et al. Metabolic profile, physical activity, and mortality in breast cancer patients. Breast Cancer Res Treat 2010;121(3):651-60.

[20] Chen JL, Lerner D, Ruthazer R, Castaneda-Sceppa C, Levey AS. Association of physical activity with mortality in chronic kidney disease. J Nephrol 2008;21(2):243-52.

[21] Nothlings U, Ford ES, Kroger J, Boeing H. Lifestyle factors and mortality among adults with diabetes: findings from the European Prospective Investigation into Cancer and Nutrition-Potsdam study*. J Diabetes 2010;2(2):112-7.

[22] Holtermann A, Burr H, Hansen JV, Krause N, Sogaard K, Mortensen OS. Occupational physical activity and mortality among Danish workers. Int Arch Occup Environ Health 2011;85(3):305-10.

[23] Holtermann A, Mortensen OS, Burr H, Sogaard K, Gyntelberg F, Suadicani P. Physica work demands, hypertension status, and risk of ischemic heart disease and all-cause mortality in the Copenhagen Male Study. Scand J Work Environ Health 2010;36(6):466-72.

[24] Vepsäläinen T, Soinio M, Lehto S, Juutilainen A, Laakso M, Rönnemaa T. Proteinuria modifies the effects of physical activity on total and cardiovascular disease mortality rates in patients with type 2 diabetes. Diabetologia 2010;53(9):1886-9.

[25] Paganini-Hill A, Kawas CH, Corrada MM. Activities and mortality in the elderly: the Leisure World cohort study. J Gerontol A Biol Sci Med Sci 2011;66(5):559-67.

[26] Schnohr P, Marott JL, Jensen JS, Jensen GB. Intensity versus duration of cycling, impact on all-cause and coronary heart disease mortality: the Copenhagen City Heart Study. Eur J Prev Cardiol 2012;19(1):73-80.

[27] Hu G, Eriksson J, Barengo NC, et al. Occupational, commuting, and leisure-time physical activity in relation to total and cardiovascular mortality among Finnish subjects with type 2 diabetes. Circulation 2004;110(6):666-73.

[28] Andersen LL, Clausen T, Persson R, Holtermann A. Dose-response relation between perceived physical exertion during healthcare work and risk of long-term sickness absence. Scand J Work Environ Health 2012;38(6):582-9.

[29] Meyer P, Kayser B, Mach F. Stair use for cardiovascular disease prevention. Eur ] Cardiovasc Prev Rehabil 2009;16(Suppl. 2):S17-8.

[30] West RR, Jones DA, Henderson AH. Rehabilitation after myocardial infarction trial (RAMIT): multi-centre randomised controlled trial of comprehensive cardiac rehabilitation in patients following acute myocardial infarction. Heart 2012:98(8):637-44.

[31] O'Connor CM, Whellan DJ, Lee KL, et al. Efficacy and safety of exercise training in patients with chronic heart failure: HF-ACTION randomized controlled trial. JAMA 2009;301(14):1439-50.

[32] Charansonney OL, Despres JP. Disease prevention-should we target obesity or sedentary lifestyle? Nat Rev Cardiol 2010;7(8):468-72.

[33] Sassen B, Cornelissen VA, Kiers H, Wittink H, Kok G, Vanhees L. Physical fitness matters more than physical activity in controlling cardiovascular disease risk factors. J Cardiovasc Risk 2009;16(6):677-83.

[34] Bankoski A, Harris TB, McClain JJ, et al. Sedentary activity associated with metabolic syndrome independent of physical activity. Diabetes Care 2011;34(2):497-503.

[35] Stamatakis E, Hamer M, Dunstan DW. Screen-based entertainment time, all-cause mortality, and cardiovascular events: population-based study with ongoing mortality and hospital events follow-up. J Am Coll Cardiol 2011;57(3):292-9.

[36] Levine JA. Nonexercise activity thermogenesis-liberating the life-force. J Intern Med 2007;262(3):273-87.

[37] Buchner DM, Wagner EH. Preventing frail health. Clin Geriatr Med 1992;8(1):1-17

[38] Charansonney OL. Physical activity and aging: a life-long story. Discov Med 2011;12(64):177-85.

[39] Mills EJ, O'Regan C, Eyawo O, et al. Intensive statin therapy compared with moderate dosing for prevention of cardiovascular events: a meta-analysis of $>40000$ patients. Eur Heart J 2011;32(11):1409-15.

[40] Meador BM, Huey KA. Statin-associated myopathy and its exacerbation with exercise. Muscle Nerve 2010;42(4):469-79.

[41] Kokkinos PF, Faselis C, Myers J, Panagiotakos D, Doumas M. Interactive effects of fitness and statin treatment on mortality risk in veterans with dyslipidaemia: a cohort study. Lancet 2013;381(9864):394-9.

[42] Mascitelli L, Goldstein MR. Statin and exercise prescription. Lancet 2013:381(9878):1622.

[43] McAlister FA, Wiebe N, Ezekowitz JA, Leung AA, Armstrong PW. Meta-analysis: $\beta$ blocker dose, heart rate reduction, and death in patients with heart failure. Ann Intern Med 2009;150(11):784-94.

[44] Gelbrich G, Edelmann F, Inkrot S, et al. Is target dose the treatment target? Uptitrating beta-blockers for heart failure in the elderly. Int J Cardiol 2012;155(1):160-6.

[45] Kaminsky LA, Arena R, Beckie TM, et al. The importance of cardiorespiratory fitness in the United States: the need for a national registry: a policy statement from the American Heart Association. Circulation 2013;127(5):652-62.

[46] Armitage J, Bowman L, Wallendszus K, et al. Intensive lowering of LDL cholesterol with $80 \mathrm{mg}$ versus $20 \mathrm{mg}$ simvastatin daily in 12,064 survivors of myocardial infarction: a double-blind randomised trial. Lancet 2010;376(9753):1658-69. 